\title{
ТЕОРЕТИЧЕСКИЕ ОСНОВЫ МЕХАНИЗМА ФОРМИРОВАНИЯ ГОСУДАРСТВЕННОЙ ПОЛИТИКИ РОССИИ НА БАЗЕ СИСТЕМНОГО ПОДХОДА
}

Аннотация: Статья посвящена теоретическим основам формирования государственной политики Российской Федерации на Дальнем Востоке. Автор приходит к выводу, что стратегическими приоритетами руководства страны являются: во-первых, сохранение государства и модернизация, во-вторых, переходк интенсивной стратегии исторического развития. Придерживаясь стратегии равноудаленности от мировых лидеров, с акиентом на манипулятивном использовании противоречий между иентрами сил.

Ключевые слова: Политология, системный подход, национально-государственные интересы, угрозы, приграничный регион, уровни координации, пограничная политика, государственная политика, стратегия, равноудаленность

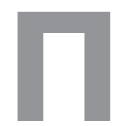
роцесс трансформации политической и экономической жизни в мире порождает проблемы и вызовы XXI века, решение которых требует от государств создания новой системы политического взаимодействия и взаимного учета национальных интересов.

Существуют различные различные модели социального взаимодействия, рассматривая механизм формирования государственной национальной политики России на Дальнем Востоке и в частности, к проблеме пограничной политики, мы приходим к выводу о необходимости интегративного, системного подхода к решению поставленной задачи.

Используя системный подход к общественным и национальным интересам, мы имеем возможность органично переплести их друг между другом и заставить функционировать по общим законам сложносоставной и многоуровневой системы. При этом мы надеемся, что, находясь в постоянном взаимодействии между собой, они обнаружат целостность и структурную соподчиненность, которые предполагают в том числе и наличие в системе национальных интересов функциональных связей координации. Это позволит согласовать различные, в том числе не совпадающие интересы в единой целостной структуре. Используя при этом субординацию, мы сможем вычленить приоритеты, непосредственно зависящие от конкретных условий существования и развития нации.
Таким образом, системный подход, позволяющий одновременно учитывать и общественные, и национальные интересы России, даст нам ожидаемый синергетический эффект в развитии региона. Кроме того, он позволит сформировать лояльное отношение населения к проводимым мероприятиям и получить поддержку жителей страны даже из отдаленных регионов. Это, в свою очередь, дает возможность создать эффект защищенности у населения, а также демонстрацию заботы государства о приграничных территориях.

Мы не оспариваем тот факт, что на современном этапе развития мировой политической системы одним из приоритетных направления для Российской федерации является формирование внешнеполитической стратегии развития. От того насколько верно и быстро нашему государству удастся вписаться в складывающуюся международную систему зависит реализация национально-государственных интересов, но и дальнейшая судьба.

История мирового развития показывает, что национально-государственные интересы изменяются под воздействием трансформации в составе правящей элиты общества, политических сил внутри страны, в мировой системе. Примером могут служить СССР после начала перестройки, Россия после 1991 года, октябрьские события 1993 г. Вместе с тем в структуре национально-государственных интересов есть и смысловое объективное ядро, сохраняющееся несмотря не на что. Это принцип обеспечения жизнедеятельности 
DOI: 10.7256/1811-9018.2013.7.5894

При цитировании этой статьи сноска на dоі обязательна

\section{Право и политика 7 (163) • 2013}

государства. Данный принцип помогает обеспечить сохранность нации и определить перспективы развития. Исходя из этого, мы убеждены, что национально-государственные интересы представляют собой целостную взаимосвязанную систему интересов, которая никоим образом не исключает наличие противоречий и конфликтов внутри государства. Более того, определяет системный характер потребностей и интересов как общества в целом, так и отдельных его индивидуумов.

Как мы отметили выше, система национальногосударственных интересов предполагает наличие функциональных связей и структуры данной системы. Структура в свою очередь обусловлена наличием национальных интересов в различных сферах жизнедеятельности человека, общества и государства. Из всей известной классификации национальных интересов мы бы выделили политические, экономические, этнокультурные, религиозные и др. Кроме этого, всю сферу жизнедеятельности государства следует разделить на внешнюю и внутреннюю. К этому следует добавить, что функциональные связи также следует разделить по механизму правового регулирования на императивные и диспозитивные (субординации, координации, корелляции). Координационные связи помогают согласовывать, в том числе и не совпадающие интересы в единой целостной системе. Причем согласованность может достигаться за счет предпочтения одной группе интересов за счет другой. К примеру, социальная справедливость за счет экономической эффективности. Однако государственная система должна позволять снимать или сводить до минимума те напряжения, которые возникают в силу игнорирования некоторых из них.

Необходимо отметить, что связи субординации способствуют определению приоритетов в системе национально-государственных интересов.

Таким образом, учитывая вышесказанное главной целью внешнеполитической стратегии должно стать социально-экономическое и политическое возрождение России, как одной из крупнейших и развитых держав мира. При этом сохраняя свою национальнокультурную специфику, гуманистических характер отношений и демократическую форму управления. Более того, необходимо определить основные технологии, формы и методы осуществления задач, учитывая возможные риски и рассмотрев результаты применения различных средств.

При выборе стратегического курса внешнеполитической деятельности России должны лежать следующие принципы:

- незыблемость коренных и основных национально-государственных интересов, при гибком маневрировании второстепенными интересами;
- приоритетность внутренних национальных интересов;

- коллективный подход к решению глобальных проблем;

- равенство акторов системы межгосударственных отношений ${ }^{1}$;

- равные права каждого государства при выборе пути развития и уважение этого выбора;

- предпочтение коллективных систем безопасности национальным. Данный принцип обеспечения безопасности предполагает не наращивание собственной военной мощи государства, а создание на региональном или глобальном уровне эффективных механизмов международной безопасности под эгидой ООН;

- мирное решение международных споров и конфликтов, поиск компромиссов; системность формирования и реализации внешнеполитической стратегии. Этот принцип предполагает строгую иерархию и согласованность стратегических и тактических целей, главенство внешнеполитической стратегии над тактикой, умелое использование политической конъюнктуры, противоречий среди акторов, дипломатическое сотрудничество с заинтересованными сторонами в решении наиболее важных международных проблем.

В настоящее время приграничные регионы стали весьма уязвимой и болевой частью всей сферы государственной безопасности России. Именно эти пространства становятся основными и потенциальными источниками повышенной опасности для территориальной целостности страны. Эти факторы диктуют частичное установление «закрытой» системы с жестким режимом контроля и охраны границы на участках с наиболее напряженной и опасной для интересов страны военнополитической обстановкой. Специфичность условий функционирования пограничной службы на различных участках границы страны и чрезвычайно разные состояния пограничных отношений оказывают влияние на пограничную политику, требуя от нее своевременного реагирования на возникающие проблемы и их незамедлительного решения. Государственная граница и приграничные территории государств различны по своим формам развития, что определяло и в прошлом, и в настоящем специфику выработки пограничных программ сосуществования, - адекватно отражающих политические, экономические, культурные, этнические, конфессиональные особенности в том или ином пограничном регионе.

Следует отметить, что, прежде всего, само понятие «пограничный регион» определяется как часть государ-

\footnotetext{
${ }^{1}$ Каждое государство должно получить равные права в мировом сообществе, что потребует пересмотра Устава ООН, не изменявшегося в течение 50 лет.
} 
ственной территории, примыкающей к государственной границе, где осуществляется деятельность пограничных служб, и реализуется пограничная политика страны. В связи с этим обстоятельством структурой региональной организации органов Пограничной службы ФСБ РФ на приграничной территории России в настоящее время выделяется 36 управлений: по Амурской, Архангельской, Астраханской, Белгородской и Воронежской, Брянской, Калининградской, Курской, Курганской и Тюменской, Мурманской и др. Мы рассмотрим Дальневосточный пограничный регион, на территории которого функционирует 5 пограничных управлений, а также он объединяет в своем составе 9 субъектов Российской Федерации.

Естественно, что особое значение для целенаправленной и согласованной деятельности всех компонентов системы обеспечения пограничной безопасности страны имеет адекватная современным реальностям и требованиям пограничная политика государства (Российской Федерации) ${ }^{2}$ - государственная пограничная политика как фактор укрепления пограничной безопасности страны и целостности системы ее обеспечения. Системный подход к ее формированию позволил бы, как минимум, обеспечить повышение ее эффективности при сохранении существующих расходов на национальную безопасность в этом регионе. При этом под системным подходом в данном случае мы имеем в виду и налаживание контактов с местным населением, которое еще с советских времен продемонстрировало, что лояльность местных жителей государственной политике сама по себе является залогом сохранности целостности приграничных территорий.

Надо сказать, что закрепление и определение понятия «государственная пограничная политика» или «пограничная политика России» можно найти в «Положении о Межведомственной комиссии Совета Безопасности Российской Федерации по пограничной политике», утвержденном Указом Президента Российской Федерации от 27 февраля 1995 г. № 211 и в «Положении о Пограничной службе Российской Федерации», утвержденном Приказом Директора Федеральной службы безопасности РФ в 2008 г. Кроме того, для исключения ведомственного толкования вводится в оборот словосочетание «государственная пограничная политика Российской Федерации». При этом Комиссия является «основным рабочим органом Совета Безопасности Российской Федерации по выработке и реализации государственной пограничной политики Российской Федерации».

${ }^{2}$ Садовский В.Н. Основания общей теории систем. - М., Наука, 1974. - C. 83-84. URL: http://lib.mexmat.ru/books/70913 (дата обращения 25.07.2010)
Кроме этого на Комиссию возложена обязанность определять основные направления государственной пограничной политики Российской Федерации. Однако приоритетные направления в документе не конкретизированы, вместе с тем обязывает их выделять и планировать деятельность органов государственной власти и местного самоуправления и обеспечивать их реализацию.

Пограничная политика России как явление представляет собой линию поведения государства на государственной границе и в пограничной сфере в целом, имеющую давние исторические традиции. Однако существует круг проблем в данной сфере, которые по своему характеру относятся к предмету ведения именно пограничной политики.

Сам термин «пограничная политика государства» является сравнительно новым. Он не получил еще достаточно широкого политологического признания, нормативно-правового закрепления и применения в международной и отечественной политической практике. Дело, по всей видимости, в том, что во многих странах вопросы, относящиеся к компетенции пограничной политики, не образуют самостоятельного направления политики государства, регулируются в рамках внешней, военной (оборонной), правоохранительной политики. Однако в государствах, имеющих обширную территорию и граничащих со значительным числом сопредельных стран, существует необходимость в выработке и проведении самостоятельной пограничной политики. Закономерным следствием этого стало появление и документально-правовое закрепление термина «пограничная политика государства».

Важно отметить, что пограничная политика - это политика на линии взаимопересечения внешней и внутренней политики.

Далее рассматривая вопрос правового регулирования обеспечения пограничной безопасности Российской Федерации, нельзя не отметить, что до настоящего времени в научной и служебной литературе не получили глубокого освещения правовые основы Государственной границы Российской Федерации, ее защиты и охраны, реализации пограничной политики, интеграции и сотрудничества по пограничным вопросам. К этому следует добавить, что, несмотря на неоднократное освещение проблемных вопросов пограничной сферы государства учеными-юристами, специалистами-практиками, исследующими правовой статус государственной границы, юридические и иные проблемы ее защиты и охраны в своих научных трудах - разработка соответствующих правовых основ, детально регламентирующих деятельность субъектов защиты и охраны Государственной гра- 


\section{Право и политика 7 (163) • 2013}

ницы и стратегическую линию обеспечения национальной безопасности России в пограничной сфере, не завершена ${ }^{3}$.

В настоящее время насчитывается несколько сот законодательных и иных нормативных правовых актов, в той или иной степени регулирующих отношения в сфере пограничной безопасности России. Их анализ показывает, что они создают достаточно разветвленную правовую базу реализации пограничной политики России и деятельности федеральных органов исполнительной власти, их территориальных (региональных) структур по обеспечению пограничной безопасности ${ }^{4}$.

Пограничная политика Российской Федерации представляет собой систему официально принятых взглядов на цель, задачи, принципы, основные направления, решения и мероприятия по реализации пограничной политики Российской Федерации ${ }^{5}$.

При этом основными субъектами пограничной политики Российской Федерации являются: федеральные органы государственной власти; органы государственной власти субъектов Российской Федерации; органы местного самоуправления; общественные объединения, организации и граждане.

В то же время к основным объектам пограничной политики Российской Федерации следует отнести государственную границу РФ, национальные интересы России в ее пограничном пространстве, а также на внешних границах государств - участников СНГ.

Среди основных направлений пограничной политики мы бы выделили следующие:

- совершенствование международно-правового оформления Государственной границы Российской Федерации;

\footnotetext{
3 Чеканов В.E. Правовые основы пограничной безопасности Российской Федерации. Материалы научно-практической конференции Московского военного института ФПС РФ URL: http:// voenprav.ru/doc-3464-1.htm (дата обращения 17.05.2010)

${ }^{4}$ Справочно: Прежде всего, это Конституция Российской Федерации, Стратегия национальной безопасности Российской Федерации до 2020 г., Основы пограничной политики Российской Федерации, законы: «О Государственной границе Российской Федерации», «О Пограничной службе Российской Федерации», «О безопасности», «Об обороне», «О континентальном шельфе Российской Федерации», «Об исключительной экономической зоне Российской Федерации», «О внутренних морских водах, территориальном море и прилежащей зоне Российской Федерации», «О порядке выезда из Российской Федерации и въезда в Российскую Федерацию», а также нормативные правовые акты, регламентирующие деятельность в пограничной сфере федеральных органов исполнительной власти, органов государственной власти субъектов Российской Федерации, органов местного самоуправления, общественных организаций и граждан.

${ }^{5}$ Основы Пограничной политики Российской Федерации // URL: http//ps.fsb.ru/general/info/details.htm (дата обращения: 17.08.2010)
}

- обеспечение пограничной безопасности Российской Федерации;

- развитие межгосударственного пограничного сотрудничества;

- обеспечение национальной и коллективной безопасности на внешних границах государств-участников СНГ;

- развитие социально-экономической и духовной основы жизнедеятельности приграничных регионов Российской Федерации;

формирование и развитие системы научных знаний в области пограничной политики ${ }^{6}$.

В настоящее время остро встала проблема координации деятельности различных ведомств в пограничном пространстве. В настоящее время в сфере фронтира работает более 20-ти министерств и ведомств, около 45-ти субъектов Российской Федерации активно действуют в пограничном пространстве. По всей вероятности, все это способствовало наделению Пограничной службы ФСБ РФ специальными функциями.

В то же время реализация пограничной политики России осуществляется в общей системе обеспечения национальной безопасности посредством скоординированной деятельности федеральных органов государственной власти, органов государственной власти субъектов Российской Федерации, органов местного самоуправления, общественных объединений, организаций и граждан на основе законодательства Российской Федерации.

Основные направления пограничной политики Российской Федерации реализуются не только при разработке федеральных целевых программ, но и при осуществлении внешнеполитической, экономической, военной, социальной, финансовой и экологической деятельности государства, т.е. являются следствием связи внутри- и внешнеполитической деятельности государственного аппарата.

Пограничная политика Российской Федерации осуществляется в пограничном пространстве $\mathrm{P}^{7}$ Российской

\footnotetext{
${ }^{6}$ Основы пограничной политики Российской Федерации: Указ Президента Российской Федерации от 5 октября 1996 г. № Пр-1987 // Сборник нормативных правовых актов. Вып. VII. Безопасность, оборона, государственная граница. - М., 1998. - С. 126-127.

7 Пограничное пространство - 1. Зона, охватывающая государственную границу, пункты пропуска через государственную границу и связанные с ними объекты внутри страны, приграничную территорию, воздушное пространство, трансграничные (пограничные) водные объекты, внутренние морские воды, территориальное море, их подводную среду, континентальный шельф и исключительную экономическую зону Российской Федерации. Концепция охраны Государственной границы, внутренних морских вод, территориального моря, континентального шельфа, исключительной экономической зоны Российской Федера-
} 
Федерации, охватывающем государственную границу Российской Федерации, пункты пропуска через государственную границу и связанные с ними объекты внутри страны, приграничную территорию, воздушное пространство, трансграничные (пограничные) водные объекты, акватории территориального моря и внутренних вод, подводную среду, континентальный шельф и исключительную экономическую зону Российской Федерации. Многогранное пограничное пространство как совокупность процессов и явлений, связанных с государственной границей, с межгосударственным разграничением и взаимодействием раскрывается во взаимосвязях и взаимодействии определенных социально-экономических систем - государств и лишь в определенном их взаимодействии и взаимосвязи - пограничных отношениях.

Пограничные отношения имеют ряд особенностей: во-первых, неоднородность и устойчивость, которая обусловлена наличием государств с различными политико-экономическими, социально-культурными и духовными отношениями; во-вторых, определенность, которая определяется потребностями государства в сохранении своих существенных признаков; в-третьих, связанность, обусловленная общностью границ и развитием трансграничного сотрудничества; в-четвертых, социальная направленность деятельности занятых в пограничном пространстве в целях обеспечения пограничной безопасности.

Для того, чтобы объединить все эти особенности, необходим описанный выше системный подход. Общественные и национальные интересы в пограничных отношениях должны рассматриваться комплексно, с учетом интересов не только стран-партнеров, но и собственного населения Дальнего Востока.

Показательно, что государственная граница представляет собой специфический регулятор и индикатор отношений между государствами. Какими они должны быть - это и определяет государственная пограничная политика.

ции и их природных ресурсов на 2001-2005 гг. Утверждена Указом Президента РФ

1 сентября 2001 г. 2. Социально-географическая зона вдоль границы или вдоль пункта в глубине территории страны, в пределах которой наблюдаются пограничные процессы и явления, связанные с интересами соседних стран и взаимодействием между их экономическими, культурными, правовыми и политическими системами. В число функциональных элементов П.П. входят пограничные институты и системы, пограничные отношения, пограничные нормы и правовые режимы, индивидуальные и общественные мнения, взгляды и убеждения См.: Кудияров В. Пограничные пространства России. - Границы России. 1996, - № 2, - С. 77-83; Хвощеев B.E., Муллаянов Р.Ш. Пограничная политика и безопасность. Опыт регионального анализа. Челябинск, 2001, - С. 25.
Более того, в настоящее время, когда угрозы национальным интересам России усугубляются ограниченностью ресурсного обеспечения их защиты, государство стремится проводить такую пограничную политику, которая, с одной стороны, отражала бы интересы вхождения страны в международные политические и социально-экономические отношения, а с другой - предотвращала бы попытки причинения ей какого бы то ни было ущерба, всесторонне обеспечивала ее пограничную безопасность.

Основными задачами пограничной политики Российской Федерации являются: обеспечение суверенитета и территориальной целостности государства; межгосударственное сотрудничество по предотвращению военной опасности, кризисов и конфликтов в пограничном пространстве; создание условий для защиты национальных интересов в пограничном пространстве страны; пресечение терроризма, организованной преступности и криминальных элементов, действующих через границу и в пограничном пространстве; противодействие экономической, демографической, культурной и другим видам экспансии, незаконной миграции иностранных граждан и лиц без гражданства; обеспечение интересов и безопасности России на внешних границах государств-участников СНГ на основе международных договоров ${ }^{8}$.

К этому следует добавить, что необходимость реализации данных задач обусловлена существованием таких угроз безопасности интересам Российской Федерации в пограничной сфере, как:

- $\quad$ незавершенность международно-правового оформления государственной границы Российской Федерации и разграничения национальной территории с рядом сопредельных государств (Япония, США);

- $\quad$ расширение экономической, демографической и культурно-религиозной экспансии сопредельных государств на российскую территорию;

- $\quad$ активизация деятельности транснациональной организованной преступности (ТОП) ${ }^{9}$ по контрабанде материальных ценностей, наркотиков, оружия, расхищению природных ресурсов, а также зарубежных террористических организаций;

\footnotetext{
${ }^{8}$ Основы пограничной политики Российской Федерации (дата обращения 18.10.2010).

${ }^{9}$ Транснациональная организованная преступность - это негативное социальное явление, характеризующееся сложными видами преступной деятельности, осуществляемой в широких масштабах и посягающей на общественные отношения, интересы или блага, охраняемые уголовными законодательствами двух и более государств, имеющей целью, как правило, получение финансовой прибыли или приобретение власти.
} 
DOI: 10.7256/1811-9018.2013.7.5894

При цитировании этой статьи сноска на dоі обязательна

\section{Право и политика 7 (163) • 2013}

- нестабильность обстановки в приграничных регионах России вследствие снижения жизненного уровня населения, этнических, межконфессиональных и иных конфликтов;

- $\quad$ активизация деятельности на территории России иностранных специальных служб и используемых ими организаций и т. д $^{10}$.

Объединение усилий федеральных органов, их региональных структур и органов государственной власти субъектов Российской Федерации позволяет устранить возникающие между ними противоречия, устоявшиеся стереотипы, которые порождают «разночтения» и, в конечном счете, приводят к стихийным разобщенным действиям, что не способствует защите интересов России на государственной границе и приграничных территориях. Только координация деятельности федеральных органов, их региональных структур и органов государственной власти субъектов Российской Федерации позволяет решить поставленные задачи в сфере защиты и охраны государственной границы и приграничных территорий.

Сущность координации в данном случае проявляется в согласовании целей, задач, планов, содержания и форм деятельности, ресурсного потенциала всех государственных органов и других полномочных структур, обеспечивающих пограничную безопасность Российской Федерации. Ее основная цель состоит в достижении взаимопонимания, согласованности и единства действий в интересах максимальной эффективности использования возможностей федеральных и иных органов государственной власти при защите интересов России в пограничных пространствах, поддержании надежной безопасности ее границ. Реализуется она общими усилиями всех субъектов координации в рамках системного подхода и с учетом интересов и специфики их деятельности, на основе совместно выработанных программ и планов действий. Это позволит учесть максимальное количество факторов, влияющих на результаты и эффективность проводимых действий.

Надо признать, что в странах Запада уже давно получило признание и широко практикуется в различных сферах деятельности координационное управление и сотрудничество. Оно реализуется через множество различных координационных центров, советов, комитетов, организаций. В данном случае можно привести в пример деятельность Координационного комитета по экспортному контролю (КОКОМ) - неофициальной международной организации западных держав, которая действует

${ }^{10}$ Щербаков А. Н. Пограничная безопасность - важнейшая составляющая часть безопасности России и Граница России. - М., 1999. - № 1. - C.5-6. под эгидой США и НАТО и постоянно дискриминирует в вопросах торговли нашу страну.

В данном документе в области безопасности сотрудничество американцев с союзниками охватывает такие сферы, как совместная подготовка и проведение боевых учений, координация военных планов и разработок, обмен разведывательными данными, совместная разработка новых систем и осуществление контроля над экспортом секретных технологий в соответствии с общими стандартами, совместное противодействие терроризму, незаконной миграции и наркотрафику.

Представляется, что в современных условиях координация усилий в сфере защиты и охраны государственной границы, предупреждения и парирования угроз безопасности страны в пограничном пространстве с учетом ее геополитического положения, имеет целый ряд уровней и аспектов (сторон) проявления. Что касается уровней, то представляется вполне логичным выделить следующие из них: межгосударственный, федеральный (межведомственный), региональный и местный. С учетом системного подхода развитие событий на всех четырех обозначенных уровнях должно происходить не последовательно, а параллельно, то есть одновременно.

Межгосударственный уровень обеспечивает, прежде всего, координацию усилий ФСБ России с органами (войсками) пограничной охраны сопредельных государств, зарубежными дипломатическими представительствами и консульствами, иммиграционными и таможенными службами, заинтересованными международными организациями. На данном уровне происходит организация и планирование, а также практическое решение задач совместной охраны внешних рубежей Содружества Независимых Государств пограничными органами и пограничными войсками России и других государств СНГ.

Федеральный (межведомственный) уровень нацелен на согласование деятельности ФСБ России с другими министерствами, ведомствами, комитетами России на государственной границе и в приграничных территориях.

Региональный уровень обеспечивает взаимосогласование действий региональных управлений ПС ФСБ России (групп войск) с органами власти субъектов Российской Федерации, объединениями и соединениями МО РФ, республиканскими, краевыми и областными структурами и подразделениями МВД, ФТС РФ, соответствующими региональными органами других министерств, ведомств, учреждений и организаций, обладающими полномочиями в сфере защиты и охраны государственной границы.

Местный уровень координации позволяет согласовывать действия частей и подразделений органов Пограничной службы ФСБ России с городскими, 
районными, поселковыми и сельскими органами самоуправления, предприятиями и учреждениями, частями и подразделениями МО, МВД, ФТС и другими государственными органами на местах, а также с юридическими и физическими лицами. Весьма важными направлениями координационной деятельности здесь является взаимодействие пограничных структур с городскими, районными, поселковыми и сельскими органами самоуправления по привлечению местного населения к проводимым мероприятиям по защите и охране границы.

Вследствие этого решение задачи предупреждения и парирование внешних угроз интересам и безопасности Российской Федерации в пограничном пространстве, обусловленных изменениями в геополитическом положении страны, предполагает последовательное выполнение субъектами реализации пограничной политики ряда действий ${ }^{11}$ :

- уяснение политических, экономических, военно-стратегических, духовно-информационных, национально-этнических, демографических, религиозных и иных интересов России в пограничном пространстве применительно к конкретному приграничному региону (регионам);

- выявление на основе учета геополитического положения внешних сил давления, которые противодействуют достижению интересов страны в приграничном регионе (регионах) и порождают угрозы пограничной безопасности;

- установление конкретных внешних угроз пограничной безопасности и прогнозирование возможных последствий их реализации в приграничном регионе (регионах) без осуществления мер противодействия;

- $\quad$ выявление внешних угроз, в предупреждении которых в приграничном регионе (регионах) гарантированно участвуют федеральные силы, уточнение угроз, в предупреждении которых могут участвовать региональные субъекты пограничной политики;

- $\quad$ разработка практических мероприятий по предупреждению проявления и развития в пригра-

\footnotetext{
${ }^{11}$ Взаимосвязь между пограничной политикой и угрозами безопасности страны в пограничном пространстве / Гришин М.Л., Губченко В.Н., Дмитриев В.Л. и др. Проблемы пограничной политики государства и пути их решения: Монография: БДУ-пресс, 2001. - С. 76-77; Кулаков Л.В. Система геополитических факторов и ее влияние на пограничную политику Российской Федерации: Автореф. дис докт. филос. наук. - М.: ЛФПС РФ, 2000. - С. 41; Шумов В.В. К вопросу назначения требуемой степени нейтрализации угроз безопасности России в пограничных регионах / Сборн. статей отделения погранологии международной Академии информатизации. Вып. 4. - М.: Отделение погранологии МАИ, 1997. - С. 35-38; и др.
}

ничном регионе (регионах) разносторонних и многоплановых внешних угроз (в сфере политики, экономики, обороны, обеспечения безопасности, этноконфессиональных отношений и т. п.);

- определение возможностей региональных субъектов пограничной политики по предупреждению возникающих угроз и сопоставление их с объемом мероприятий по парированию внешних угроз, а также необходимых дополнительных сил и средств для оказания помощи субъектам пограничной политики региона в предупреждении внешних угроз;

- у уточнение внешних угроз, которые не могут быть предупреждены в результате проведения соответствующих мероприятий, и которые с большой вероятностью потребуется парировать;

- определение гарантированной нейтрализации внешних угроз, а также разработка комплекса конкретных мер по предупреждению и парированию выявленных в данном регионе внешних угроз пограничной безопасности страны;

- постановка задач субъектам пограничной политики региона, федеральным силам и средствам усиления и поддержки по предупреждению и парированию реальных и возможных внешних угроз, а также определение объема работы по целенаправленной подготовке к выполнению намеченных мероприятий;

- у уточнение по мере изменения обстановки в данном пограничном регионе намеченных мероприятий по предупреждению и парированию внешних угроз, а также задач субъектам пограничной политики, федеральным силам и средствам их усиления и поддержки ${ }^{12}$.

Итак, последовательная реализация выше изложенного предполагает выявление интересов страны на границе и в приграничном регионе ${ }^{13}$ (регионах). Здесь, помимо учета геополитического и геостратегического положения России, тенденций изменения геополитической ситуации в мире, места и роли страны в системе

\footnotetext{
12 Основы пограничной политики Российской Федерации // URL.:http//ps.fsb.ru/general/info/details.htm (дата обращения: 8.10.2010).

${ }^{13}$ Приграничные регионы представляют собой категорию территориальных субъектов государства, для которых основной капитал международного сотрудничества носит территориально-географический характер. Их специфика состоит, во-первых, в том, что из-за особого отношения государства к своим внешним границам все эти регионы неизбежно вплетены в сложную комбинацию факторов, связанных с геополитикой, геоэкономикой и безопасностью. См.: Вардомский Л.Б., Голунов С.В. Прозрачные границы. Безопасность и трансграничное сотрудничество в зоне новых пограничных территорий России. - Калуга, ГУП Облиздат, 2002. - С.529.
} 
DOI: $10.7256 / 1811-9018.2013 .7 .5894$

При цитировании этой статьи сноска на dоі обязательна

\section{Право и политика 7 (163) 2013}

мировых и региональных международных отношений, характера связей с сопредельными государствами, необходима конкретизация состояния обстановки в приграничном регионе (регионах) в области обороны и состояния пограничной безопасности ${ }^{14}$, а также политических, экономических, социальных, этноконфессиональных отношений.

После выявления имеющихся в соответствующем приграничном регионе (регионах) интересов Российского государства необходимо определить внешние силы давления, которые могут противодействовать их реализации. В качестве таковых могут выступать: отдельные государства и их союзы (коалиции); политические, религиозные, экономические и другие организации; отдельные лица и группы (объединения) людей.

Необходимо выявление именно реальных внешних угроз, проявляющихся в приграничном регионе (регионах) в соответствующих сферах деятельности государственных органов, общества и личности, их ранжирование по степени важности.

В настоящее время далеко не единичными стали факты попыток нарушения границы вооруженными формированиями, внезапного вооруженного нападения на пограничные заставы и иные объекты, незаконного перемещения через границу контрабандных товаров и материалов целыми вагонами, морскими судами и автомашинами. Проведение пограничных поисков, операций, других служебно-боевых и оперативно-служебных действий, что в прошлом было явлением эпизодическим, теперь превращаются в обычное повседневное дело пограничных войск на многих участках государственной границы. И все это происходит в период, когда соединения и части не укомплектованы личным составом и техникой, испытывают трудности с материально-техническим снабжением.

Таким образом, одним из приоритетных направлений противодействия угрозам безопасности России в пограничном пространстве, обусловленных ее геополитическим положением, выступает усиление координации действий федеральных и региональных органов власти по их своевременному предупреждению и парированию (нейтрализации).

\footnotetext{
${ }^{14}$ Пограничную безопасность можно определить как приемлемое для правящей элиты и общественного мнения соответствующей страны состояние защищенности пределов ее территории от опасных трансграничных потоков и условий, как правило подразумевающих серьезное нарушение территориальной целостности государства и установленного пограничного режима. См.: Голунов $C$. Безопасность пограничных пространств. //Международные процессы. URL: http://www.intertrends.ru/fourteen/003 (дата обращения: 4.04.2011)
}

Необходимость усиления координации действий по предупреждению и парированию внешних угроз безопасности страны на границе и приграничных территориях обусловливается изменившимся геополитическим положением России, неоднозначными тенденциями развития международных отношений. Только консолидация сил и средств, совместные действия на основе единого замысла, четкого и продуманного планирования способны предупредить и парировать угрозы пограничной безопасности. При этом важно учитывать, что помимо федеральных и региональных органов власти субъектами противодействия внешним угрозам в пограничном пространстве выступают органы местного самоуправления, общественные объединения, а также физические и юридические лица.

Таким образом при формулировании интересов государство и общество должны, во-первых, исходить из объективной реальности существующей внутри страны и за ее пределами; во-вторых, учитывать состояние социума и государства; в-третьих, видеть цель, к которой мы хотим прийти.

Содержание национальных интересов Российской Федерации это ни что иное, как интегрированное выражение сбалансированных жизненно важных интересов личности, общества и государства. В конечном счете - это основа формирования стратегических задач внутренней и внешней политики страны.

Национальные интересы России - это совокупность внутренних и внешних потребностей государства в обеспечении защищенности и устойчивого развития личности, общества и государства.

Поскольку российское общество не нашло консенсуса по поводу базовых ценностей и стратегических целей, то сновным условием реализации предложенных планов, должен стать системный подход к разработке единой стратегии, объединяющей национальные и общественные интересы России на Дальнем Востоке. Системная интеграция планов России в деятельность международного сообщества позволит не только избежать излишней конфронтации с конкурентами, но и «держать руку на пульсе» всех международных событий, своевременно реагируя на изменения международного баланса сил.

\section{Библиография:}

1. Вардомский Л.Б., Голунов С.В. Прозрачные границы. Безопасность и трансграничное сотрудничество в зоне новых пограничных территорий России. - Калуга, ГУП Облиздат, 2002. - С.529.

2. Гришин М.Л., Губченко В.Л. Взаимосвязь между пограничной политикой и угрозами без- 
DOI: $10.7256 / 1811-9018.2013 .7 .5894$

При цитировании этой статьи сноска на dоі обязательна

Государственная безопасность

опасности страны в пограничном пространстве / Гришин М.Л., Губченко В.Н., Дмитриев В.Л. и др. Проблемы пограничной политики государства и пути их решения: Монография: БДУ-пресс, 2001. - С. 76-77.

3. Голунов С. Безопасность пограничных пространств. // Международные процессы. URL: http:// www.intertrends.ru/fourteen/003 (дата обращения: 4.04.2011).

4. Кудияров В. Пограничные пространства России. - Границы России. 1996, - № 2, -С. 77-83.

5. Кулаков Л.В. Система геополитических факторов и ее влияние на пограничную политику Российской Федерации: Автореф. дис докт. филос. наук. - М.: ЛФПС РФ, 2000. - С. 41.

6. Основы пограничной политики Российской Федерации: Указ Президента Российской Федерации от 5 октября 1996 г. № Пр-1987 // Сборник нормативных правовых актов. Вып. VII. Безопасность, оборона, государственная граница. - М., 1998. - С. 126-127.

7. Садовский В.Н. Основания общей теории систем. M., Наука, 1974. - C. 83-84. URL: http://lib.mexmat. ru/books/70913 (дата обращения 25.07.2010)

8. Хвощев В.Е., Муллаянов Р.Ш. Пограничная политика и безопасность. Опыт регионального анализа. Челябинск, 2001, - С. 25.

9. Чеканов В.Е. Правовые основы пограничной безопасности Российской Федерации. Материалы научно-практической конференции Московского военного института ФПС РФ URL: http://voenprav. ru/doc-3464-1.htm (дата обращения 17.05.2010)

10. Шумов В.В. К вопросу назначения требуемой степени нейтрализации угроз безопасности России в пограничных регионах / Сборн. статей отделения погранологии международной Академии информатизации. Вып. 4. - М.: Отделение погранологии МАИ, 1997. - С. 35-38.

11. Щербаков А. Н. Пограничная безопасность - важнейшая составляющая часть безопасности России и Граница России. - М., 1999. - № 1. - С.5-6.

\section{References (transliteration):}

1. Vardomskiy L.B., Golunov S.V. Prozrachnye granicy. Bezopasnost' i transgranichnoe sotrudnichestvo $\mathrm{v}$ zone novyh pogranichnyh territoriy Rossii. - Kaluga, GUP Oblizdat, 2002. - S.529.

2. Grishin M.L., Gubchenko V.L. Vzaimosvyaz' mezhdu pogranichnoy politikoy i ugrozami bezopasnosti strany v pogranichnom prostranstve / Grishin M.L., Gubchenko V.N., Dmitriev V.L. i dr. Problemy pogranichnoy politiki gosudarstva i puti ih resheniya: Monografiya: BDU-press, 2001. - S. 76-77.

3. Golunov S. Bezopasnost' pogranichnyh prostranstv. // Mezhdunarodnye processy. URL: http://www.intertrends.ru/fourteen/003 (data obrascheniya: 4.04.2011).

4. Kudiyarov V. Pogranichnye prostranstva Rossii. Granicy Rossii. 1996, - № 2, -S. 77-83.

5. Kulakov L.V. Sistema geopoliticheskih faktorov i ee vliyanie na pogranichnuyu politiku Rossiyskoy Federacii: Avtoref. dis dokt. filos. nauk. - M.: LFPS RF, 2000. - S. 41.

6. Sadovskiy V.N. Osnovaniya obschey teorii sistem. M., Nauka, 1974. - S. 83-84. URL: http://lib.mexmat. ru/books/70913 (data obrascheniya 25.07.2010)

7. Hvoschev V.E., Mullayanov R.Sh. Pogranichnaya politika i bezopasnost'. Opyt regional'nogo analiza. Chelyabinsk, 2001, - S. 25.

8. Chekanov V.E. Pravovye osnovy pogranichnoy bezopasnosti Rossiyskoy Federacii. Materialy nauchnoprakticheskoy konferencii Moskovskogo voennogo instituta FPS RF URL: http://voenprav.ru/doc-3464-1. htm (data obrascheniya 17.05.2010)

9. Shumov V.V. K voprosu naznacheniya trebuemoy stepeni neytralizacii ugroz bezopasnosti Rossii v pogranichnyh regionah / Sborn. statey otdeleniya pogranologii mezhdunarodnoy Akademii informatizacii. Vyp. 4. - M.: Otdelenie pogranologii MAI, 1997. - S. 35-38.

10. Scherbakov A. N. Pogranichnaya bezopasnost' vazhneyshaya sostavlyayuschaya chast' bezopasnosti Rossii i Granica Rossii. - M., 1999. - № 1. - S.5-6. 